\title{
FATIGUE FAILURE OF AN OPEN CELL AND A CLOSED CELL ALUMINIUM ALLOY FOAM
}

\author{
A.-M. HARTE, N. A. FLECK† and M. F. ASHBY \\ Engineering Department, Cambridge University, Trumpington St., Cambridge CB2 1PZ, U.K.
}

(Received 13 November 1998; accepted 2 March 1999)

\begin{abstract}
The tension-tension and compression-compression cyclic properties are measured for an open cell "Duocel" foam of composition Al 6101-T6, and a closed cell "Alporas" foam of composition Al$5 \mathrm{Ca}-3 \mathrm{Ti}(\mathrm{wt} \%)$. The Duocel foam has a relatively uniform microstructure, and undergoes homogeneous straining in both monotonic and fatigue tests. In contrast, the Alporas foam is more irregular in microstructure, and exhibits crush-band formation at random locations under uniaxial compression; in compression-compression fatigue, a single crush band forms and broadens with additional fatigue cycles Progressive shortening of the specimen in compression-compression fatigue, and progressive lengthening in tension-tension fatigue are due to a combination of low cycle fatigue failure and cyclic ratchetting. $S-N$ fatigue curves are presented for the onset of progressive shortening in the compression tests, and material separation in the tension tests; it is envisaged that such curves will be of practical use in design. (C) 1999 Acta Metallurgica Inc. Published by Elsevier Science Ltd. All rights reserved.
\end{abstract}

Keywords: Aluminium alloys; Foams; Fatigue; Plastic collapse

\section{INTRODUCTION}

Metallic foams such as aluminium alloy foams show potential for use in ultra-lightweight metallic structures. Recently, a number of aluminium suppliers around the world have produced a new range of closed cell aluminium alloy foams, for example "Alporas" foam produced by Shinko Wire in Japan, "Cymat" foam in Canada, "Alulight" foam by Mepura in Austria, and a Norske Hydro foam in Norway. These closed cell foams are produced by foaming the alloy in the liquid state or in the creep state, and are significantly cheaper than existing open cell foams. A comprehensive account of the full range of metallic foams is given by Ashby et al. [1]. Aluminium alloy foams are up to an order of magnitude stiffer and stronger than polymeric foams, and maintain their mechanical properties up to a higher temperature. It is likely that they will find application by meeting several design objectives simultaneously, such as high energy and sound absorption, fire retardance, and adequate mechanical strength.

There is mounting experimental evidence that imperfections within currently available closed cell foams lead to a significant degradation in stiffness and strength, see for example Sugimura et al. [2], Gioux et al. [3] and McCullough et al. [4]. These imperfections include cell wall wiggles and curvature, Plateau borders, missing cell edges, non-uniform relative density and an irregular cell geometry.

$\dagger$ To whom all correspondence should be addressed.

†Supplied by Energy Research and Generation, Inc., 900 Stanford Avenue, Oakland, California, U.S.A.
Such imperfections induce bending of the cell edges under all stress states, as shown in the recent theoretical study of Chen et al. [5] for two-dimensional foams, and in the three-dimensional studies of Grenestedt [6]

In structural applications of metallic foams, it is necessary to take into account the degradation of strength with cyclic loading. Under tension-tension loading, a sensible strategy is to perform conventional $S-N$ fatigue tests on the foam, and to define the fatigue life $N_{\mathrm{f}}$ under any stress range $\Delta \sigma$ as the number of cycles for separation of the fatigue specimen. But in many potential applications such as in sandwich panels, the foam core is loaded in shear or in compression. Under compression-compression fatigue loading, metallic foams fail in a different manner from that of fully dense metals: they undergo progressive crushing, and can achieve large strains prior to densification [7,8]. Therefore, an alternative definition of material failure is required in order to construct an $S-N$ curve for compression-compression loading. We shall follow the recommendation of Sugimura et al. [7] and assume that fatigue failure occurs when the foam begins to crush. It appears that no shear fatigue tests have been reported in the literature to date: this is the topic of a future investigation.

\section{MATERIALS}

We shall compare the monotonic and cyclic properties of the recently developed closed cell foam Alporas and the established open cell foam, Duocel.t Although Alporas foam is much cheaper 
than Duocel foam it has a more heterogeneous microstructure; it is of scientific and practical interest to investigate the effects of these contrasting microstructures on the mechanical properties. Typical micrographs of the microstructures of Alporas foam and of 6101-T6 Duocel foam are compared in Fig. 1. The Alporas foam has been sectioned and mounted in an opaque resin for improved visualization of the microstructure, using a technique developed by Murphy et al. [9]. It is clear that the Alporas foam has a larger diversity of imperfections than the Duocel foam.

Alporas foam, produced by Shinko Wire, $\dagger$ contains about $5 \%$ calcium in order to increase its viscosity in the molten state. The phase diagram for aluminium-calcium indicates a eutectic near this composition. $\mathrm{TiH}_{2}$ particles are stirred into the molten alloy, and decompose to form titanium and hydrogen. The $\mathrm{H}_{2}$ gas foams the melt, whilst the Ti dissolves in the Al. During foaming, an over-pressure is used to control cell size and porosity. The $\mathrm{Ti}$ and the $\mathrm{Ca}$ form precipitates of $\mathrm{Al}_{4} \mathrm{Ca}$ and perhaps $\mathrm{TiAl}_{3}$ [2]. Samples with a relative density $\bar{\rho}=8.4$, 11 and $13 \%$ were obtained from Shinko Wire; most tests were performed on Alporas foam of relative density, $11 \%$. The average cell size is about $3 \mathrm{~mm}$ for $\bar{\rho}=11$ and $13 \%$, and $5 \mathrm{~mm}$ for $\bar{\rho}=8.4 \%$.

Monotonic and cyclic tests were also performed on Duocel open cell foam, of composition Al 6101T6, of relative density $\bar{\rho}=7.0 \%$ and of cell size $1.25 \mathrm{~mm}$. The processing route for this foam is proprietary; the microstructure resembles that of a polymeric foam, and displays relatively straight cell edges. It appears that the pre-cursor polymer foam from which the aluminium foam is produced is close to an equilibrium structure in the liquid state. Consequently, we expect the foam to have excellent mechanical properties in comparison with the more defective Alporas foam.

\section{MONOTONIC RESPONSE}

Bart-Smith et al. [10] have already performed monotonic compression tests on Duocel of relative density $\bar{\rho}=8 \%$ and on Alporas foam of relative density $\bar{\rho}=11 \%$; we focus here on a comparison between the tensile and compressive responses, and the effect of relative density upon the behaviour for Alporas foam. All the monotonic and cyclic tests were performed on an Instron 8872 servo-hydraulic test machine, under computer control.

\subsection{Test method}

The tensile and compressive stress-strain responses were measured for the Alporas foam, with relative densities $\bar{\rho}=8.4,11$ and $13 \%$, and for the

$\dagger$ European supplier, Karl Bula, Innovation Serves, Ch5200 Brugg, Herrenmatt 7F, Switzerland.
Duocel foam, with relative density $\bar{\rho}=7.0 \%$. Dogbone specimens were used for the tensile tests, and cuboid shaped specimens were used for the compression tests. The dogbone specimens were of rectangular section $25 \mathrm{~mm}$ by $18 \mathrm{~mm}$ and of gauge length $30 \mathrm{~mm}$ for Duocel, and of section $25 \mathrm{~mm}$ by $30 \mathrm{~mm}$ and of gauge length $100 \mathrm{~mm}$ for Alporas. The cuboid compression specimens were of square section $50 \mathrm{~mm}$ by $50 \mathrm{~mm}$ and of gauge length about $70 \mathrm{~mm}$ for both materials. In all cases the leading dimensions of the specimens exceeded eight cell sizes, and it can be assumed that the specimens were sufficiently large to give representative material properties, free from free-surface effects [11]. The straining direction was parallel to the rise direction of the foam for the compression and tension tests of Duocel, and was transverse to the rise direction in the compression and tensile tests of Alporas; however, it is known from previous experience that Alporas foam is almost isotropic in its stress-strain response. In the monotonic tests, a nominal strain rate of $2 \times 10^{-3} / \mathrm{s}$ was applied, and a clip gauge of gauge length $12.5 \mathrm{~mm}$ was used to measure the axial strain.

\subsection{Results of monotonic tests}

Uniaxial tension and compression data are shown in Fig. 2 for both types of foam. A stretched scale is used for the tensile data in order to display the

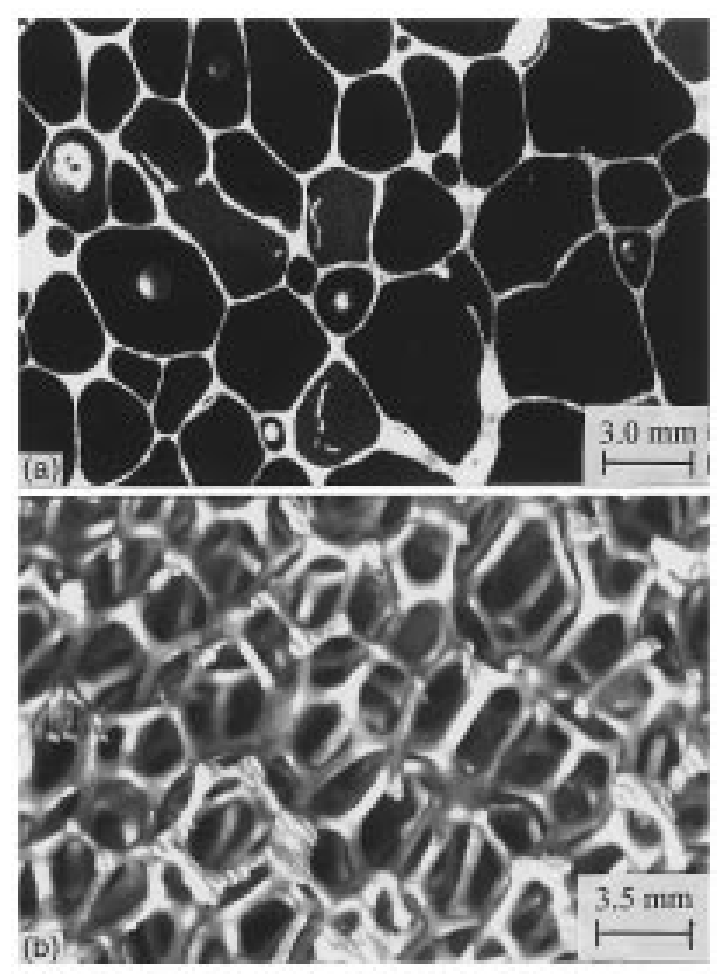

Fig. 1. Optical micrographs of (a) closed cell Alporas foam (relative density $=11 \%$ ) and (b) open cell Duocel foam (relative density $=7.0 \%$ ). 


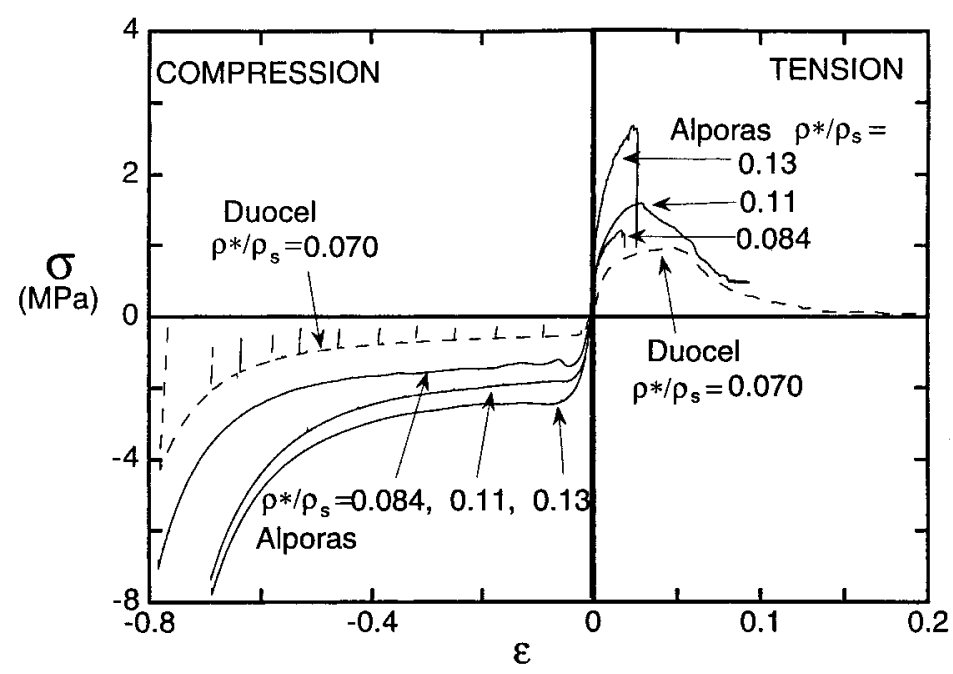

Fig. 2. Tensile and compressive monotonic responses of the Alporas and Duocel foams, with axes of nominal stress and strain.

results to adequate resolution. The difference between the tensile and the compressive responses is striking for each material. First, consider the case of uniaxial tension. A strong strain hardening behaviour is displayed, prior to tearing across the section at a nominal strain of only a few per cent. Consistent with the strong strain hardening response prior to the onset of tearing, the strain state was observed to be relatively uniform within the specimens, with no evidence of localization of deformation into a band, for both the Duocel and Alporas foams. It is thought that the maximum stress is set by necking of the cell edges, similar to the necking of a tensile bar. On recalling that the typical tensile ductility for a fully dense aluminium alloy is about $10 \%$, the reduction of tensile ductility for the foam is consistent with the notion that the presence of Plateau borders at the cell edges limits the extensional strains to the mid-portion of the cell edges.

Second, consider the compression responses. The foams crush at an almost constant plateau stress $\sigma_{\mathrm{pl}}$ until opposing cell faces touch and the stress-strain curve rises steeply. The nominal strain at which the stress-strain curve begins to rise is termed the densification strain $\varepsilon_{\mathrm{D}}$ and is of the order of 0.6 , for all the foams reported in Fig. 2. The Duocel foam compresses uniformly, with a gently rising stressstrain curve in compression, and with no evidence of the formation of discrete crush bands. In contrast, the Alporas foams crush by the sequential formation of crush bands at random sections of the foam $[2,7]$. Each crush band is normal to the loading direction, is about one cell dimension in thickness, and undergoes an average normal strain of

$\dagger$ The measured cell wall yield strength is about $190 \mathrm{MPa}$ for the Duocel foam and $150 \mathrm{MPa}$ for the Alporas foam [12]. approximately $30 \%$ (significantly less than the densification strain) prior to the formation of the next crush band. After the whole specimen has been consumed by crush bands the specimen strains uniformly. We note that the foams are ductile in compression: they can undergo much larger strains than the tensile ductility of a fully dense aluminium alloy. This suggests that the cell edges deform mainly in bending, with the bending strains in the cells much less than the macroscopic uniaxial strain.

A comparison of the stress-strain curves for the open cell Duocel foam and the closed cell Alporas foam shows that the closed cell foam is significantly stronger in tension and in compression than the open cell foam, despite the fact that the open cell foam consists of the stronger cell wall material, $\dagger$ and has the more uniform microstructure. These uniaxial data for the foams are consistent with Gibson and Ashby's [13] argument that the cell faces of a closed cell foam deform by stretching and have a disproportional effect upon the macroscopic stiffness and strength. The higher value of densification strain for the open cell foam is consistent with the observation that it has a much more regular microstructure than the Alporas closed cell foam, and thereby can pack more densely prior to lockup. Finally, we note from Fig. 2 that the yield strengths in tension and in compression are approximately equal for all the foams considered.

\section{TENSION-TENSION FATIGUE TESTS AND RESULTS}

In this section, we report the tension-tension fatigue behaviour of Alporas (relative density, $\bar{\rho}=11 \%$ ) and Duocel foams (relative density, $\bar{\rho}=7.0 \%$ ). In the following section, the compression-compression response is addressed. 


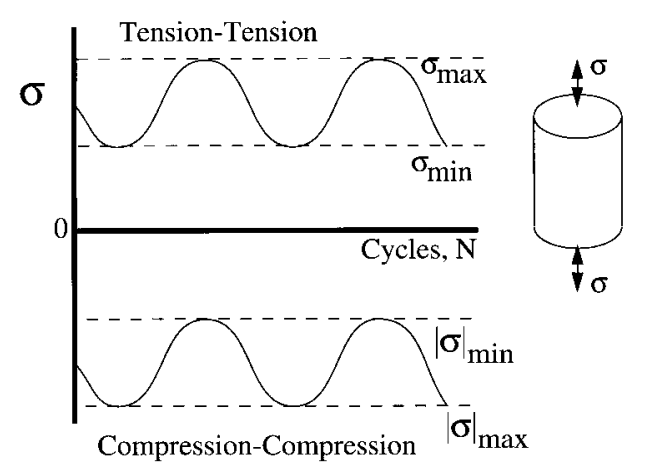

Fig. 3. Definition of the loading in tension-tension and compression-compression fatigue.

The loading is defined in Fig. 3, and the load ratio $R$ is defined by

$$
R=\frac{|\sigma|_{\min }}{|\sigma|_{\max }}
$$

Tests were performed at a fixed load range, and at a frequency of $20 \mathrm{~Hz}$. Dogbone specimens and cuboid specimens were used for tension-tension and compression-compression loading, respectively.

Tension-tension tests were performed on the Alporas and the Duocel foams using a load ratio $R=0.1$. It was observed that the specimens progressively lengthened with increasing fatigue cycles until they failed at an axial extension of $1-2 \%$, as shown in Fig. 4(a) for Duocel and in Fig. 4(b) for the Alporas foam. This failure strain is relatively insensitive to load level, and is comparable to the tensile ductility under monotonic loading.

The rate of lengthening of the foam is constant until near the end of the fatigue life of the specimen. The underlying mechanism of progressive lengthening is thought to be a combination of cyclic ratchetting and low cycle fatigue failure of the cell edges (and faces in the case of the closed cell Alporas). Towards the end of the fatigue life, a macroscopic crack initiates and propagates across the section of the specimen. This sequence of events is similar to the creep failure of metals, whereby distributed creep deformation gives way to the propagation of a single dominant crack towards the end of the creep life.

The fatigue life of the foams is defined as the number of cycles for fracture of the specimen, and is plotted as a function of the maximum stress in the fatigue cycle $\sigma_{\max }$ in Fig. 5(a) for Duocel foam and in Fig. 5(b) for Alporas foam. The data are normalized by the peak stress in a monotonic test $\sigma_{\mathrm{pl}}$ and the endurance ratio is defined here as the ratio $\sigma_{\max } / \sigma_{\mathrm{pl}}$ at a fatigue life of $10^{7}$ cycles. We deduce from the figure that the endurance ratio equals about 0.6 for both the Duocel foam and for Alporas foam. This value is comparable to that for (a)

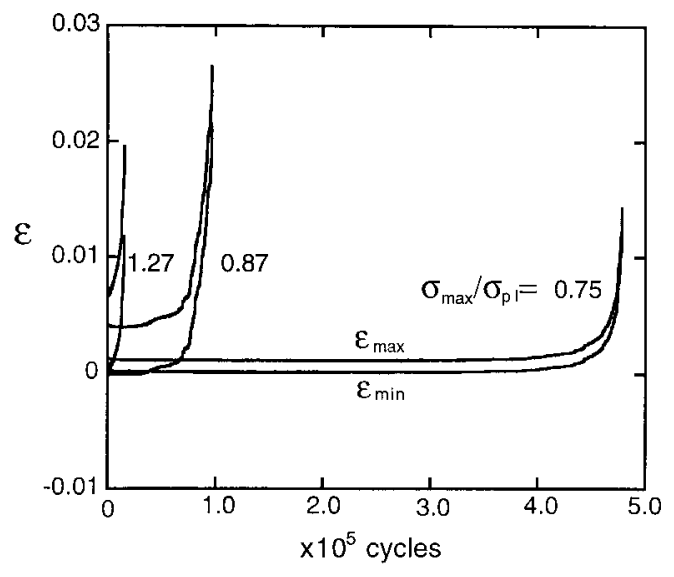

(b)

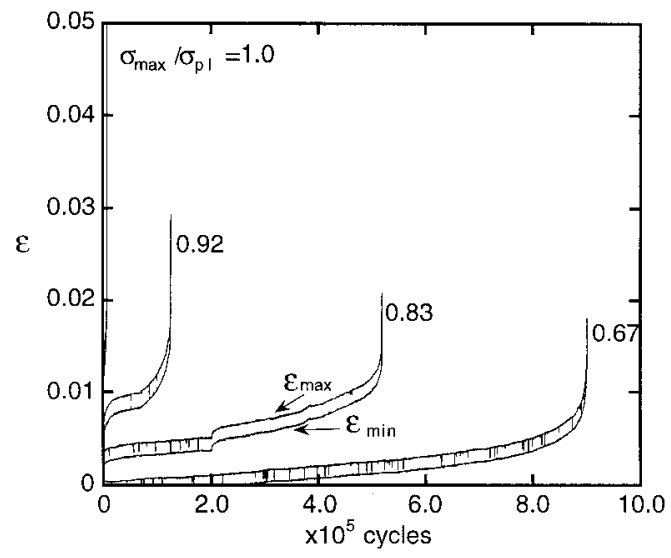

Fig. 4. Tension-tension fatigue at $R=0.1$ of (a) Duocel foam (relative density $=7.0 \%$ ) and (b) Alporas foam (relative density $=11 \%$ ).

fully dense aluminium alloys, as reviewed by Fleck et al. [14].

\section{COMPRESSION-COMPRESSION FATIGUE TESTS AND RESULTS}

Compression-compression tests were performed on the Duocel and Alporas foams and at a load ratio $R=0.1$ and 0.5 . Progressive shortening of the specimens was observed for fatigue loading of sufficient magnitude: this was quantified by data-recording the cross-head peak displacement as a function of the number of fatigue cycles. A typical plot of the shortening is sketched in Fig. 6(a): the mean value of the nominal compressive strain initially increases at a slow rate. Then, once the compressive strain has attained a value of about $2 \%$ and the associated transition number of cycles $N_{\mathrm{T}}$ has been attained, a knee in the curve of strain vs cycles is observed, and shortening increases to a new much 
(a)

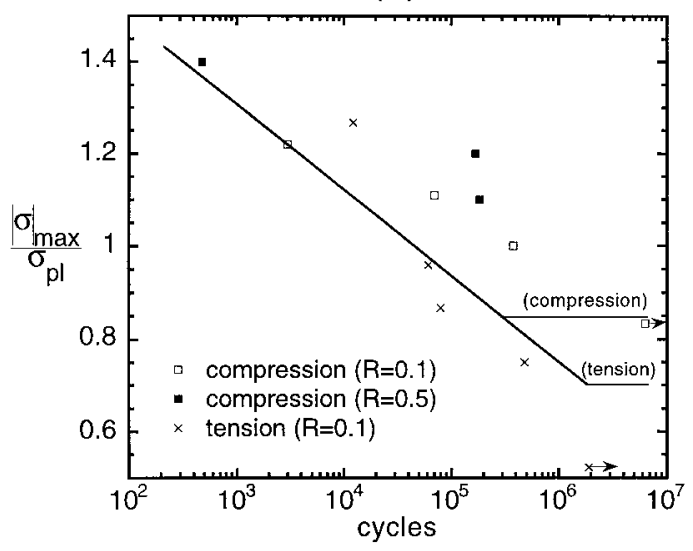

(b)

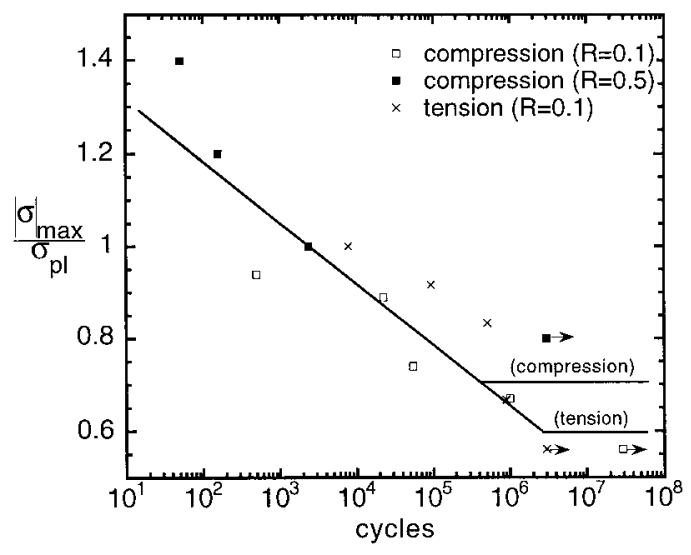

Fig. 5. $S-N$ curves for compression-compression fatigue $(R=0.1$ and 0.5$)$ and tension-tension fatigue $(R=0.1)$ :

(a) open cell Duocel foam (relative density $=7.0 \%$ ); (b) closed cell Alporas foam (relative density $=11 \%$ ).

higher rate. This phenomenon has been recorded and discussed for Alporas foam in the parallel study of Sugimura et al. [7]. In that study it was found that the initial slow rate of accumulation of compressive strain is associated with the early stages of formation of a crush band across the section of the specimen. The rapid accumulation of strain at $N>N_{\mathrm{T}}$ is due to the sequential formation of crush bands at uncorrelated locations. Sugimura et al. [7] noted steps in the trace of strain vs $N$ and found that they were associated with the discrete formation of successive crush bands [Fig. 6(b)]. Although the relative density of the Alporas tested by Sugimura et al. is nominally the same as that reported here $(11 \%)$, it is shown below that the sequence of crush-band formation is different in the two studies. In the present study, a single inclined crush band forms for $N<N_{\mathrm{T}}$ and broadens at a constant rate along the length of the specimen for $N>$

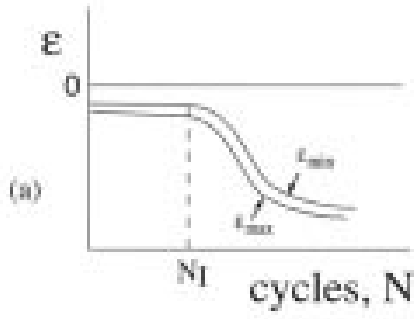

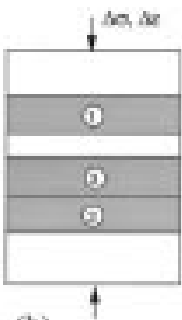

(b)

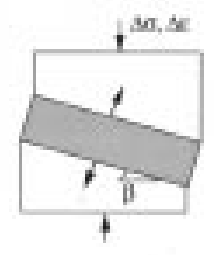

(c)
Fig. 6. (a) Schematic showing the accumulation of nominal strain with fatigue cycles. (b) Sequential crush-band formation, as observed by Sugimura et al. [7] for compression-compression fatigue of Alporas. (c) Crush-band broadening of Alporas in compression-compression fatigue, as observed in the current study.

$N_{\mathrm{T}}$ [Fig. 6(c)]. The Alporas foam used in the present study appears to have a more homogeneous microstructure than that employed by Sugimura et al. [7]; this is consistent with the observation that the monotonic plateau stress $\sigma_{\mathrm{p} 1}$ equals $1.4 \mathrm{MPa}$ in Sugimura et al. [7] compared with the value $\sigma_{\mathrm{pl}}=$ 1.9 $\mathrm{MPa}$ in the present study for the same relative density of $11 \%$.

Progressive shortening also occurs in the Duocel foam, with the same qualitative shape of straincycle response as shown in Fig. 6(a); however, straining occurs in a uniform manner without the formation of discrete crush bands. These differing responses reflect the different localization responses in a monotonic test.

The progressive shortening of the Duocel and Alporas foams are shown in Figs 7(a) and (b), respectively, for compression-compression fatigue tests performed at $R=0.1$ and 0.5 . Several general features are common to the observed responses, as follows. A slow rate of strain accumulation is evident until a knee in the curve is observed at $N=N_{\mathrm{T}}$. Thereafter, the strain accumulates rapidly with increasing cycles. The knee of the curve occurs at a compressive strain of about $2 \%$ and is used to define the "fatigue life" $N_{\mathrm{T}}$. It is instructive to cross-plot $|\sigma|_{\max }$ of the fatigue cycle (normalized by the plateau stress $\sigma_{\mathrm{pl}}$ ) against $N_{\mathrm{T}}$, and to add these data to the tension-tension $S-N$ curves shown in Fig. 5(a) for the Duocel foam and in Fig. 5(b) for the Alporas foam. It is evident that the finite life data are almost insensitive to mean stress; there is an indication that the stress level at the fatigue limit at $10^{7}$ cycles depends upon mean stress, with the fatigue limit for the tension-tension tests about 
(a)

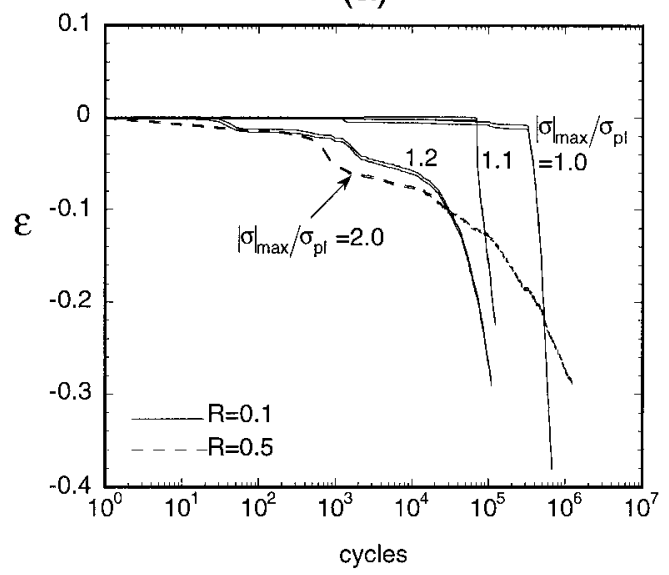

(b)

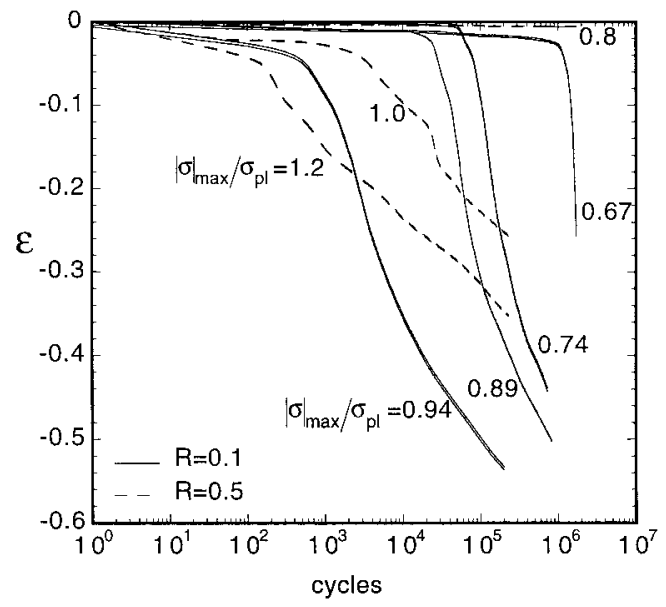

Fig. 7. Progressive shortening of (a) Duocel foam (relative density $=7.0 \%$ ) and (b) Alporas foam (relative density $=11 \%$ ), for compression-compression fatigue at

$$
R=0.1 \text { and } 0.5 \text {. }
$$

$10 \%$ below that for the compression-compression tests.

\section{PROGRESSIVE STRAINING PHENOMENA IN COMPRESSION-COMPRESSION FATIGUE}

\subsection{Shortening response of Duocel open cell foam}

Consider first the crush-band formation of the Duocel foam in more detail, for the compressioncompression fatigue case, with $R=0.1$ and $|\sigma|_{\max } / \sigma_{\mathrm{pl}}=1.11$. A plot of nominal compressive strain vs cycles, here using a linear rather than log scale, is shown in Fig. 8(a), with sketches of the deformed shape of the specimen included. The specimen strains uniformly except for a shielded wedge of foam adjacent to each grip. The specimen was

$\uparrow$ Repeat tests were performed with the face-sheets removed. There was no observable difference in the observed response. tested in the as-received state with brazed end plates of $1 \mathrm{~mm}$ thick Al 6061-T6 alloy, and so significant end constraint is to be expected. The end plates were parallel and allowed for easy testing with a well-defined end condition; the local strengthening of the foam provided by the plates resulted in plastic straining over the gauge length of the specimen and not at the grips. $\dagger$

During an initial incubation period the rate of strain accumulation is slow. Then, at $N=N_{\mathrm{T}}$ a knee in the curve occurs at a strain level of about $2 \%$. Thereafter, the specimen shortens at an increased and almost constant rate. Once the overall compressive strain in the specimen has attained a value of about 0.3 , the rate of shortening progressively decreases again. It is instructive to measure the progressive development of the strain state within the crush band with cycles. On assuming that the strain state within the crush band is uniform and consists of a combination of compression and shear, the deformation gradient $\mathbf{F}$ for material in the crush band can be deduced from the kinematics depicted in Fig. 8(b). Consider a crush band with its normal oriented at a constant angle $\beta$ to the loading direction. Assume that the crush band, of current width $w$ in the deformed configuration, originated from a band of width $w_{0}$ in the initial undeformed configuration. Then, a point A, initially at the edge of the specimen and at the boundary of the band, slides parallel to the band by a distance $s w_{0}$ to a point $\mathrm{A}^{\prime}$, and then translates a distance $\varepsilon_{\mathrm{b}} w_{0}$ to a point $\mathrm{A}^{\prime \prime}$ by a compressive nominal strain $\varepsilon_{\mathrm{b}}$ within the band. We further assume that material outside the band remains rigid, and so the direct strain along the band boundary vanishes. A material line segment $d \mathbf{x}$ in the initial configuration distorts to an element $\mathrm{d} \mathbf{y}$ in the deformed configuration, according to

$$
\mathrm{d} \mathbf{y}=\mathbf{F} \cdot \mathrm{d} \mathbf{x}
$$

where $\mathbf{F}$ is the deformation gradient. With orthogonal axes $\left(x_{1^{\prime}}, x_{2^{\prime}}\right)$ aligned with the band direction, as shown in Fig. 8(b), the components of $\mathbf{F}$ can be written as

$$
\left(F_{i j}\right)=\left(\begin{array}{cc}
1 & s \\
0 & 1-\varepsilon_{\mathrm{b}}
\end{array}\right) .
$$

We note that the sliding shear strain $s$ is related to the rotation $\phi$ of the free edge of the crush-band specimen by

$$
s=\left(1-\varepsilon_{\mathrm{b}}\right) \tan (\phi-\beta)+\tan \beta
$$

and the current width of the crush band $w$ is related to the initial width $w_{0}$ by

$$
w=\left(1-\varepsilon_{\mathrm{b}}\right) w_{0} .
$$

The crush-band width $w$ and the nominal compressive strain in the band $\varepsilon_{\mathrm{b}}$ are measured from a video recording of the fatigue test, and $w_{0}$ is found 
(b)

(a)

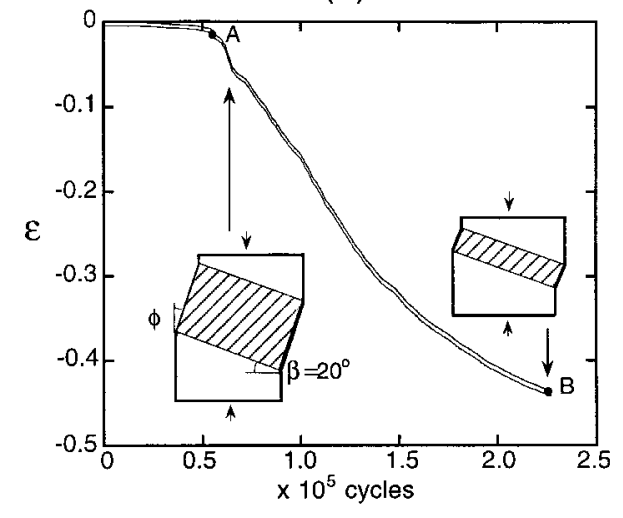

(c)

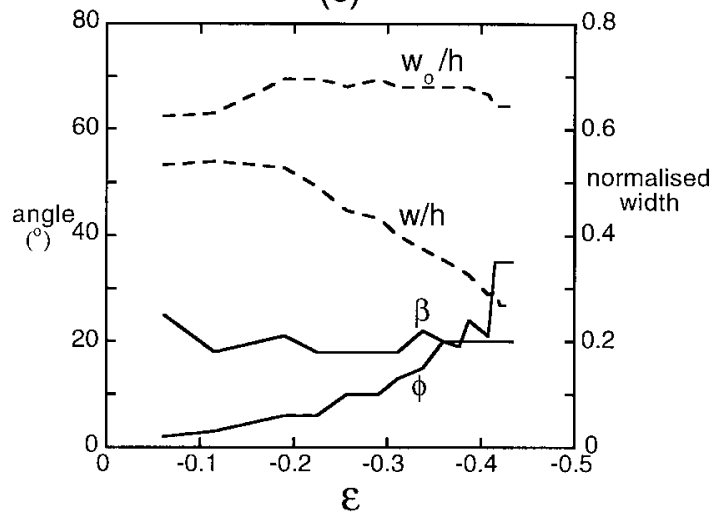

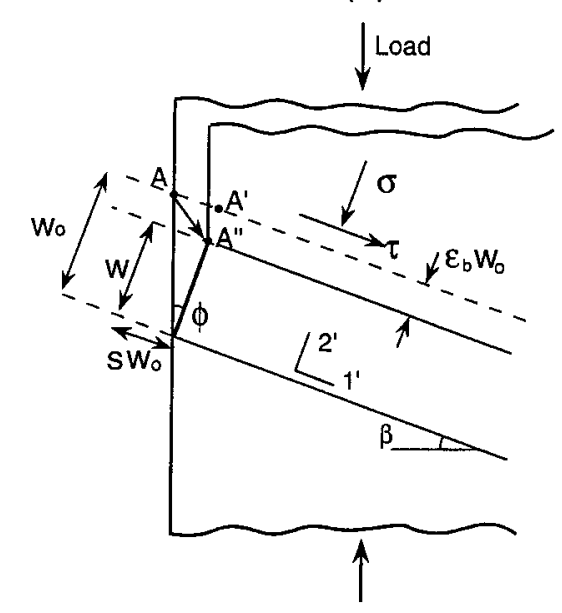

(d)

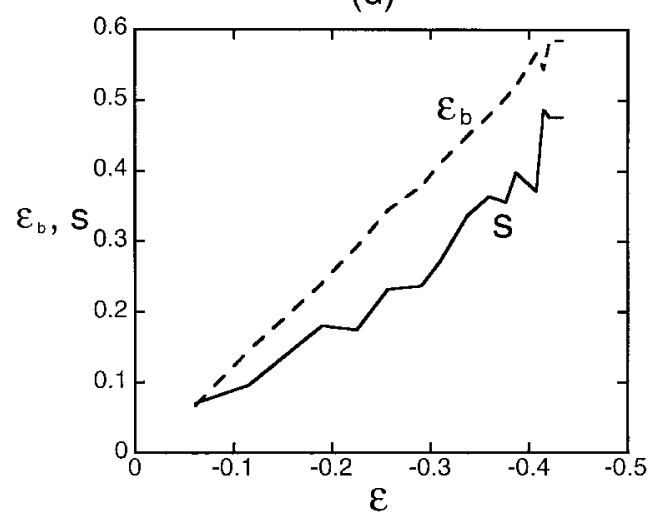

Fig. 8. Progressive shortening of Duocel foam (relative density $=7.0 \%$ ) in compression-compression fatigue, at $R=0.1$ and $|\sigma|_{\max } / \sigma_{\mathrm{pl}}=1.11$ : (a) shortening behaviour of specimen; (b) kinematics of the crush band; (c) evolution of crush-band geometry; (d) strain state in crush band; (e) photograph of overall specimen at a nominal axial strain $\varepsilon=0.02$; (f) photograph at $\varepsilon=0.22$.

by making use of equation (5). In like manner, the shear strain $s$ is deduced from equation (4) upon measuring the inclination of the crush band $\beta$, and the rotation of the side edge of the band, $\phi$.

The evolution of the crush-band inclination $\beta$ and the free edge rotation $\phi$ are plotted as a function of average compressive strain of the specimen $\varepsilon$ in Fig. 8(c) for a test on the Duocel foam, with $R=$ 0.1 and $|\sigma|_{\max } / \sigma_{\mathrm{pl}}=1.11$ [same test as shown in Fig. 8(a)]. Included in Fig. 8(c) is the width of the band in the undeformed state $w_{0}$ and the current width $w$. Values for the band width have been normalized with respect to the initial gauge length of the specimen, $h=69 \mathrm{~mm}$. We conclude that the band inclination $\beta$ is constant at $20^{\circ}$, and $w_{0} / h$ is fixed at 0.7 . The edge of the band rotates such that $\phi$ increases from zero to $35^{\circ}$ as $\varepsilon$ increases from zero to 0.43 . The strain quantities $s$ and $\varepsilon_{\mathrm{b}}$ are plotted as a function of average overall compressive strain $\varepsilon$ in Fig. 8(d). We note that $s$ and $\varepsilon_{\mathrm{b}}$ both increase in an almost linear manner with the shortening of the specimen, and attain a value of about
0.5 at $\varepsilon=0.43$. Photographs were taken of the Duocel specimen at nominal accumulated axial strains of $\varepsilon=0.02$ and 0.22 , see Figs $8(\mathrm{e})$ and (f), respectively; it is clear that the crush-band width $w$ decreases with increasing axial strain.

\subsection{Physical mechanism of fatigue}

Visual observation of the fatigued Duocel specimens revealed that extensive low cycle fatigue failure of the cell edges had occurred within the crush band. Indeed, the specimens rattled after completion of the test and debris of dimension 0.5 $1 \mathrm{~mm}$ fell freely from the open cell foam structure. Examination of such debris in the scanning electron microscope (SEM) revealed that the cellular microstructure had disintegrated into a collection of tetragonal joints, as shown in Fig. 9(a). Fatigue striations were present on the end faces of each of the struts, and confirmed the mechanism of fatigue cracking.

In order to gain insight into the significance of the low cycle fatigue failure of the cell struts, the 

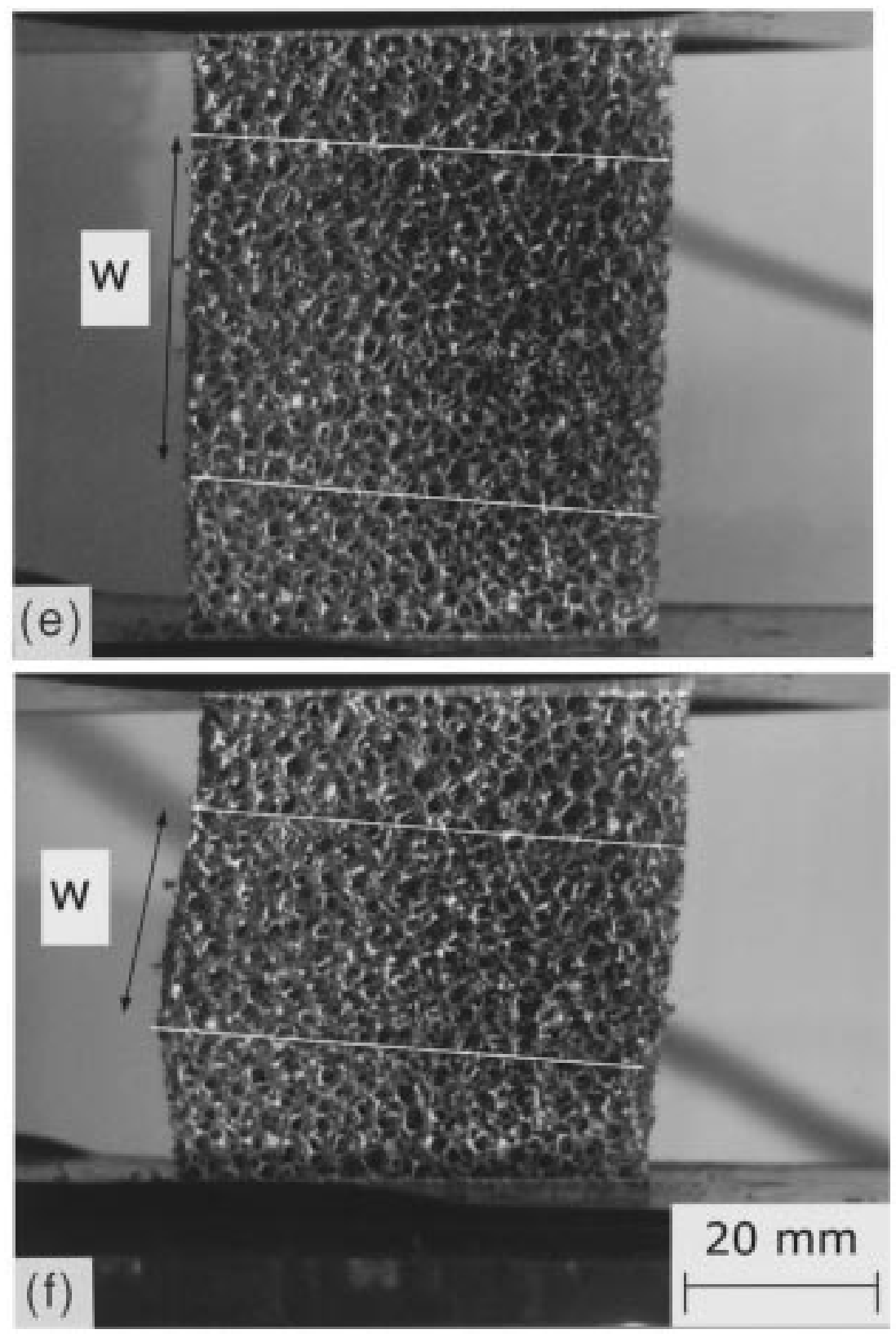

Fig 8. (continued)

unloading elastic stiffness and the electrical resistance of the specimens were measured during the fatigue tests, and were compared with the corresponding results for a monotonic test. Consider first the evolution in specimen resistance with strain for both the monotonic and cyclic tests. The electrical resistance of the specimen was measured using a d.c. potential drop technique. A constant current was applied to the specimen by connecting the top and bottom of the specimen to a $12 \mathrm{~V}$ d.c. stabilized power supply (Farnell, model B30/20) and a $4 \Omega$ resistor in series. Since the resistance of the specimen was of the order of $0.01 \Omega$, the current through the specimen was constant at $3 \mathrm{~A}$. During the monotonic and fatigue tests, the voltage across the top and bottom faces of the specimen was measured in order to measure the specimen resistance. Typical results for the voltage $V$, normalized by the initial value $V_{0}$, are given in Fig. 9(b) for both a monotonic test and a fatigue test (with $|\sigma|_{\max } / \sigma_{\mathrm{pl}}=1.0$ and $R=0.1$ ). In the monotonic tests we note that the resistance is almost constant with increasing strain, until densification occurs at a strain level of about 0.6. Beyond this point, the cell walls touch and lead to a slight drop in the electrical resistance across the two ends of the specimen. In contrast, the electrical resistance increases dramatically in the fatigue tests: at the end of the fatigue test, when the 
(a)
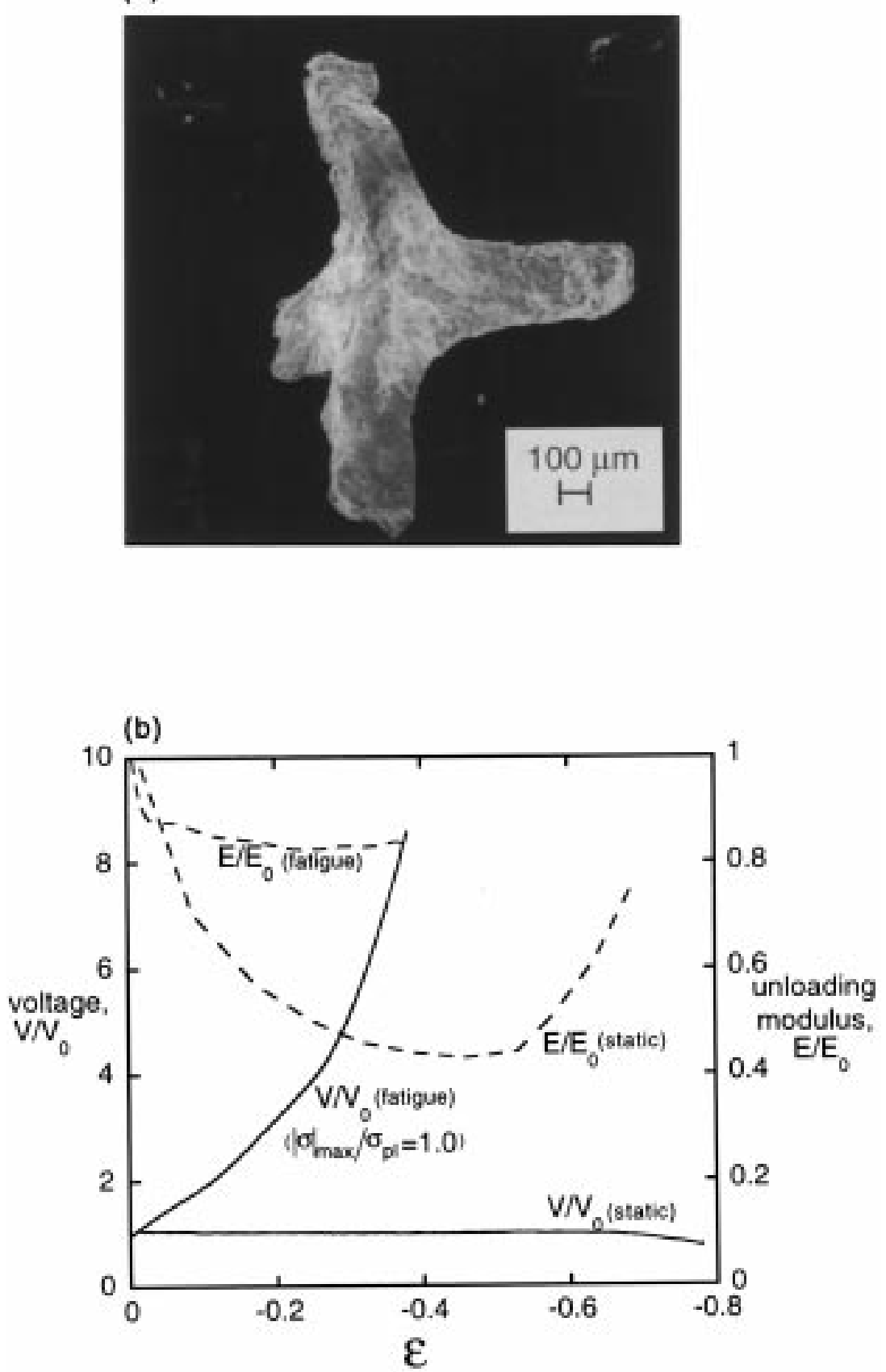

Fig. 9. (a) Scanning electron micrograph of debris from Duocel which has failed by compression-compression fatigue. (b) Electrical resistance and unloading modulus vs increasing compressive strain. Results are given for a static test, and for a cyclic test with $|\sigma|_{\max } / \sigma_{\mathrm{pl}}=1.0$ and $R=0.1$.

mean compressive strain has attained a value of 0.4 , the electrical resistance has increased by nearly an order of magnitude. This large increase in resistance is associated with the fragmentation of the specimen into discrete pieces as shown in Fig. 9(a). Such a dramatic increase in the electrical resistance suggests that a potential drop technique may be a practical method for monitoring fatigue damage development in the metallic foam cores of sandwich panels.
Next, consider the evolution of unloading modulus with strain. In the monotonic tests, the unloading modulus was measured by periodically interrupting the test at compressive strain increments of a few per cent, and by unloading the specimen by about $10 \%$. The unloading modulus was calculated from the change in axial strain corresponding to the $10 \%$ drop in load; both the stress and strain measures used in the definition of the 
unloading modulus are true values, based upon the current state. The specimen was then re-loaded and the test was resumed. In the fatigue tests the unloading modulus was calculated from the change in axial strain upon reducing the applied stress from $|\sigma|_{\max }$ to $|\sigma|_{\min }$ in each fatigue cycle. Again, the stress and strain measures used in defining the unloading modulus are true values, based upon the current state. A typical plot of unloading modulus $E$ normalized by the initial value $E_{0}$ is shown in Fig. 9(b) for a monotonic test, and for a fatigue test $\left(|\sigma|_{\max } / \sigma_{\mathrm{pl}}=1.0, R=0.1\right)$. For the monotonic test, we observe a drop in modulus by a factor of about two when the compressive strain has increased to the densification value of about 0.5; thereafter, densification leads to a sharp rise in unloading modulus. In fatigue, there is only a drop of about $20 \%$ in the unloading modulus with increasing strain. Visual observation of the specimen during the fatigue tests revealed that the specimen fragmented into many small tetragonal pieces, as shown in Fig. 9(a). This crushed material retains significant stiffness in compression, but was found to possess negligible tensile strength.

\subsection{Progressive shortening of annealed Duocel foam}

In order to explore the effect of heat treatment on fatigue response, a single Duocel specimen was subjected to a full anneal at $275^{\circ} \mathrm{C}$ for $1 \mathrm{~h}$, followed by a slow furnace cool. This specimen was then subjected to compression-compression fatigue at a load ratio $R=0.1$. The results are given in Fig. 10(a). First, the specimen was loaded monotonically until the plateau stress was attained at $\sigma_{\mathrm{pl}}=0.35 \mathrm{MPa}$, which is $32 \%$ less than the value $\sigma_{\mathrm{pl}}=0.52 \mathrm{MPa}$ for the T6 condition. Second, fatigue loading was commenced with a maximum stress of the fatigue cycle $|\sigma|_{\max }$ set at $1.1 \sigma_{\mathrm{pl}}$. This loading gave negligible progressive shortening of the specimen, and so the load was increased to $|\sigma|_{\max } / \sigma_{\mathrm{pl}}=1.2$. Again, only a slight shortening was observed with increasing fatigue cycles, and so the load was increased in additional steps, and the amount of progressive shortening was recorded, as shown in Fig. 10(a). It was found that the specimen progressively shortened but only at much higher normalized load levels than for the Duocel foam in the T6 condition. The rate of strain accumulation of fatigue cycles $\mathrm{d} \varepsilon / \mathrm{d} N$ is plotted against normalized stress level $|\sigma|_{\max } / \sigma_{\mathrm{pl}}$ in Fig. 10(b) for both the annealed and T6 conditions. For the T6 condition, the accumulation rate $\mathrm{d} \varepsilon / \mathrm{d} N$ was deduced from the number of fatigue cycles required to increase the mean strain from 0.1 to 0.4 from the series of tests at fixed $|\sigma|_{\max }$, as reported above. It is clear from Fig. 10(b) that the rate of strain accumulation is much higher for the Duocel foam in the T6 condition than in the annealed condition, for the same value of normalized stress level. A power law relation is noted between the measured $\mathrm{d} \varepsilon / \mathrm{d} N$ and (a)

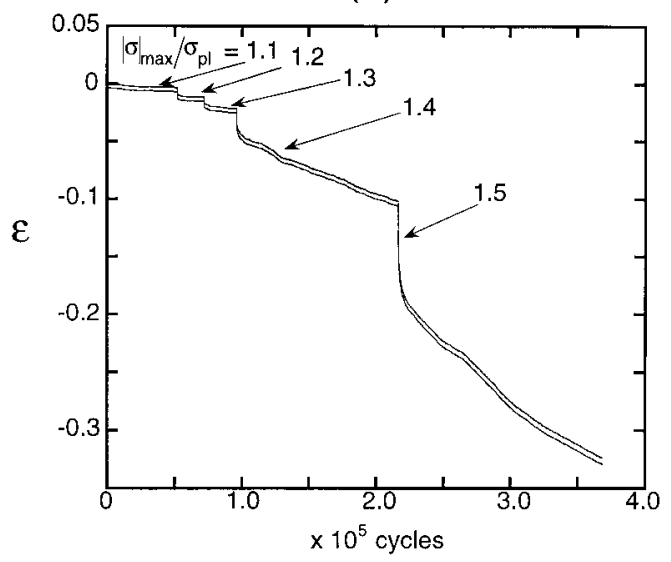

(b)

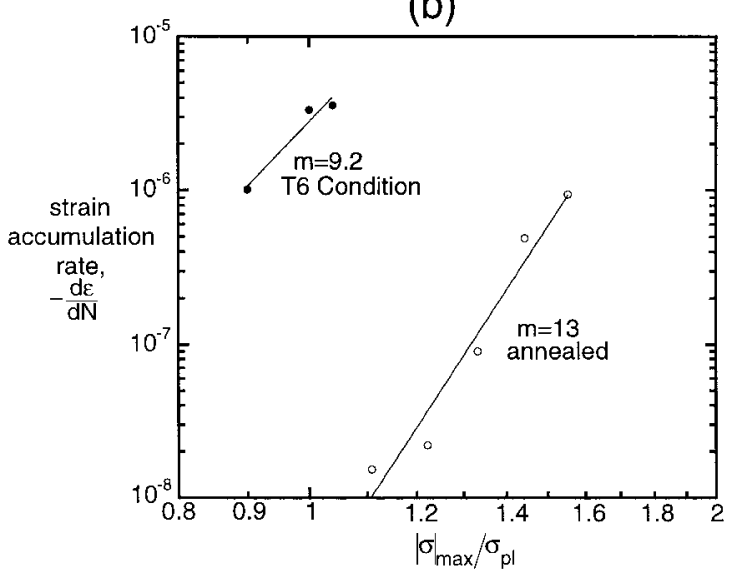

Fig. 10. (a) Compression-compression fatigue of annealed Duocel specimen, of relative density $7.0 \%$ and at a load ratio $R=0.1$. (b) The relationship between the rate of strain accumulation with load level for Duocel foam in the annealed and T6 conditions. $R=0.1$ for all tests.

$|\sigma|_{\max } / \sigma_{\mathrm{pl}}$ in Fig. 10(b). The power law index, as given by the slope on the $\log -\log$ plot, is about 9 for the T6 condition and about 13 for the annealed condition. These values are sufficiently high to suggest that a damage accumulation approach is not practical in design: the rate of strain accumulation is very sensitive to the stress level. A design methodology based on the fatigue limit is more appropriate.

The potential drop method was also used to monitor the electrical resistance of the fatigued specimen in the annealed condition. No observable change in resistance was observed during the fatigue test, suggesting that minimal cracking of the cell edges occurred. Visual observation of the deformed cellular microstructure confirmed that the progressive shortening was due to plastic bending of struts and not to fatigue cracking. It is thought that the underlying physical mechanism of progressive shortening of the annealed Duocel foam is cyclic ratchetting of the struts driven by the mean stress of the 
(a)

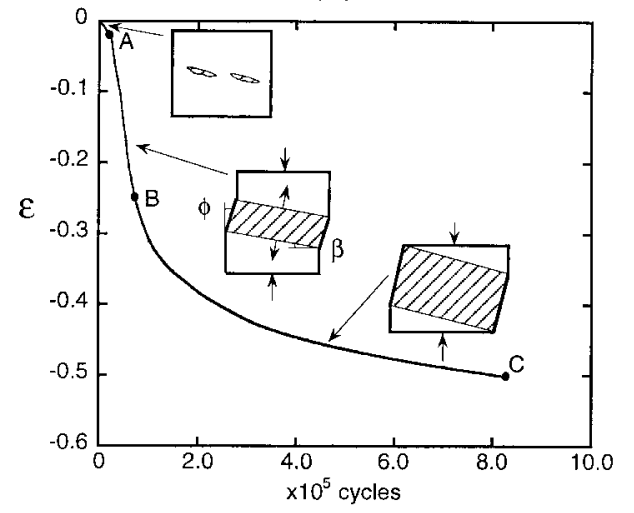

(d)

(b)

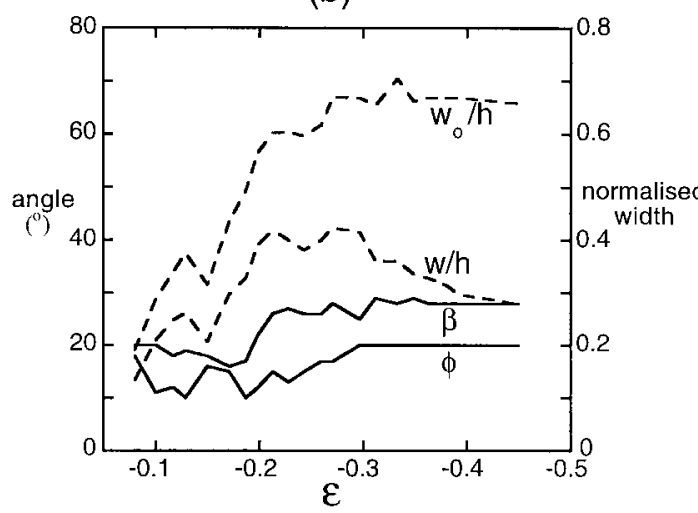

(c)
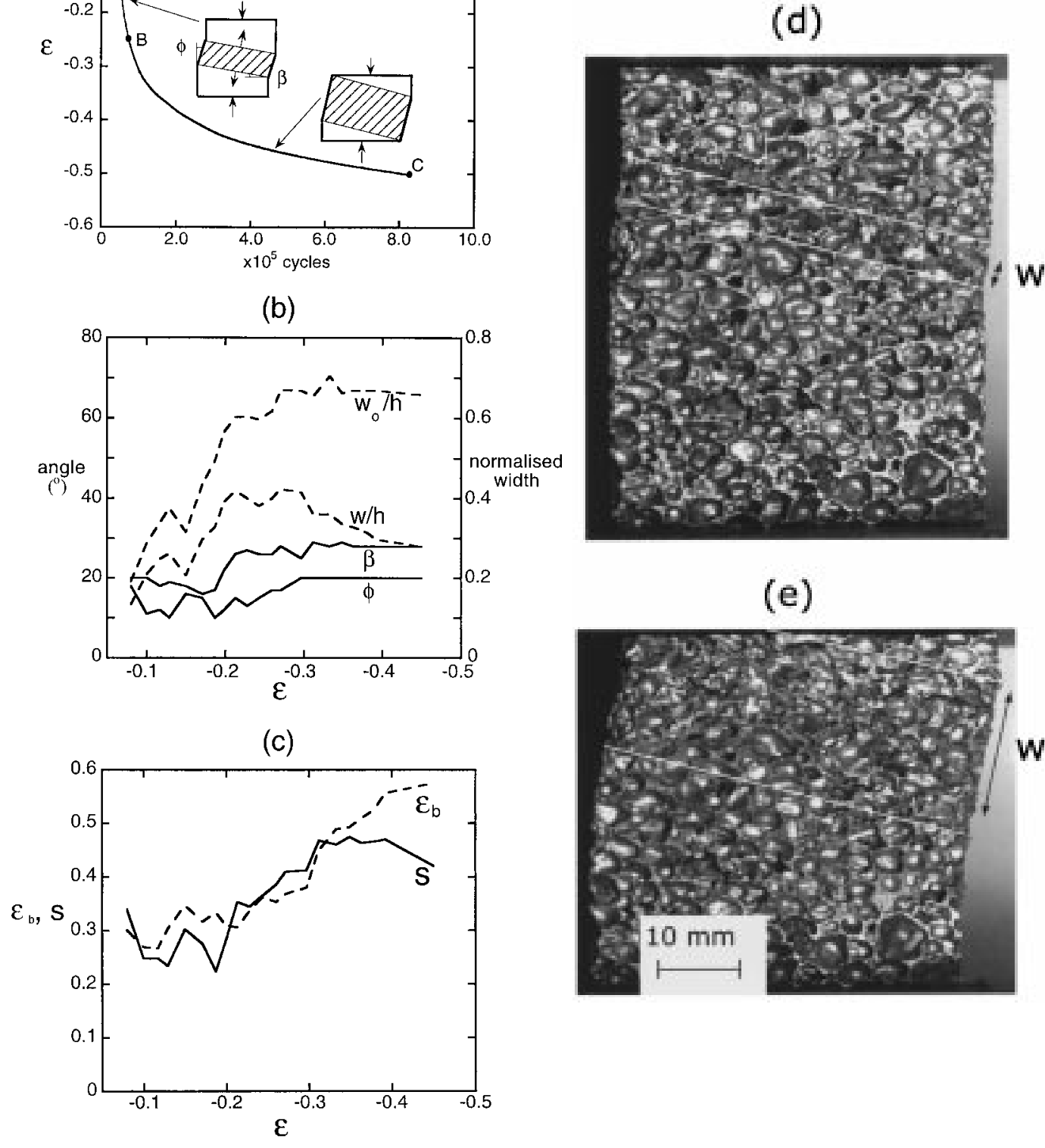

(e)

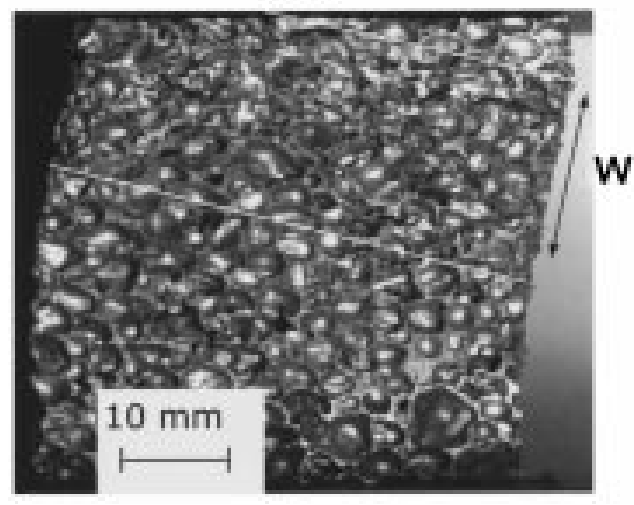

(f)

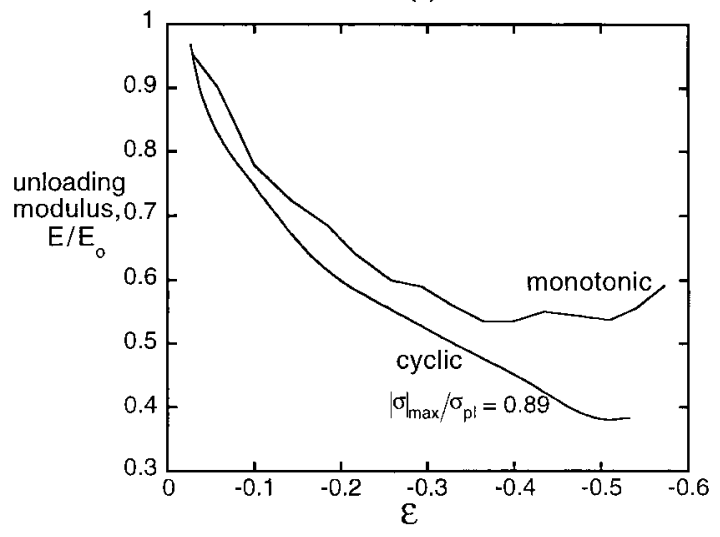

Fig. 11. (Caption overleaf) 


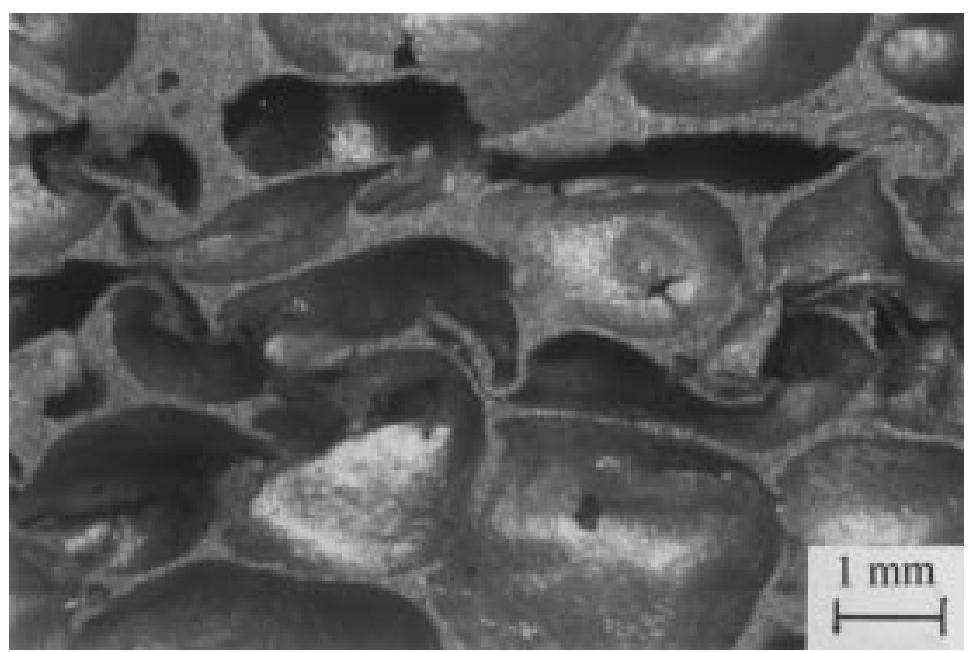

Fig. 12. Optical micrograph of the mid-section of a fatigued Alporas specimen, after compression-compression fatigue loading with $R=0.1$ and $|\sigma|_{\max } / \sigma_{\mathrm{pl}}=0.80$. Loading is in the vertical direction.

fatigue cycle. Cyclic softening of the aluminium alloy is not believed to contribute to the behaviour of the foam. A comparison of the monotonic and cyclic yield behaviours of aluminium alloys suggests that aluminium alloys of similar composition to those of Duocel and Alporas do not cyclically soften [15]

\subsection{Shortening response of Alporas closed cell foam}

At a load ratio $R=0.1$ the closed cell Alporas foam underwent progressive shortening in fatigue by the formation and then broadening of a crush band along the length of the specimen. This sequence is sketched in Fig. 11(a) alongside a plot of mean strain vs cycles, for the case $|\sigma|_{\max } / \sigma_{\mathrm{pl}}=$ 0.889 and $R=0.1$. Early in the fatigue life, the rate of strain accumulation is slow, and a single crush band forms across the width of the specimen. Then, at point $\mathrm{A}$ of the strain-life curve, the band begins to broaden. During the phase $\mathrm{A}-\mathrm{B}$ marked on Fig. 11(a) the band broadens at almost constant rate. Thereafter, the band has consumed the specimen, except in a shielded region in the vicinity of the loading grips, and the rate of strain accumulation slows down again.

The average value of the deformation gradient $\mathbf{F}$ within the crush band has been measured from video recordings of the specimen; the evolution of the width $w_{0}$ in the undeformed configuration, the current width $w$ in the deformed state, the band inclination $\beta$, and the rotation $\phi$ are shown in Fig. 11(b) for the test reported in Fig. 11(a). Note that $w_{0}$ and $w$ are normalized by the initial height $h=75 \mathrm{~mm}$ of the specimen. The associated evolution of sliding shear strain $s$ and normal strain $\varepsilon_{\mathrm{b}}$ with average axial strain $\varepsilon$ are given in Fig. 11(c), upon making use of equations (3)-(5). It is clear from Figs 11(b) and (c) that a band of constant inclination $\beta \approx 25^{\circ}$ broadens at a constant rate with a constant state of average strain in the crush band, as the overall axial strain $\varepsilon$ increases from zero to about 0.25 [stage $\mathrm{A}-\mathrm{B}$ in Fig. 11(a)]. At larger values of overall strain $\varepsilon$ the band no longer broadens, and the band width $w_{0}$ in the undeformed state remains constant. A continued increase of strain within the band leads to a narrowing of the band current width $w$, and to a continued shortening of the specimen. This final phase of behaviour is similar to that displayed by the Al 6101-T6 Duocel foam in fatigue. Photographs of the Alporas specimen were taken at nominal axial strains of $\varepsilon=0.15$ and 0.30, and are shown in Figs 11(d) and (e). The crush band begins as a single layer of cells before sweeping through the specimen.

The evolution of unloading modulus in fatigue is compared in Fig. 11(f) with that from a monotonic test. The behaviours are similar, with a drop in the average, effective modulus of the specimen by $60 \%$ when the axial strain has increased from zero to about 0.5 . The crushed microstructure in a fatigued specimen $\left(|\sigma|_{\max } / \sigma_{\mathrm{pl}}=0.8, \quad R=0.1, \quad \varepsilon=0.35\right) \quad$ is shown in Fig. 12. The local deformation state is similar to those reported by Bart-Smith et al. [10] for monotonic loading and by Sugimura et al. [7]

\footnotetext{
Fig. 11 (see previous page) Compressive strain accumulation with fatigue cycles for Alporas foam, for $|\sigma|_{\max } / \sigma_{\mathrm{pl}}=0.89, R=0.1$ and relative density $=11 \%$. (a) Axial strain vs cycles; the values of maximum and minimum strain in each cycle overlap in the figure. (b) The evolution of crush-band geometry. (c) The strain state in the crush band. (d) Photograph of side view of the overall specimen, taken at $\varepsilon=0.15$. The loading direction is vertical. (e) Photograph of overall specimen at $\varepsilon=0.30$. (f) Evolution of effective modulus with compressive nominal strain in the fatigue test. Data for a monotonic test have been added for comparison.
} 


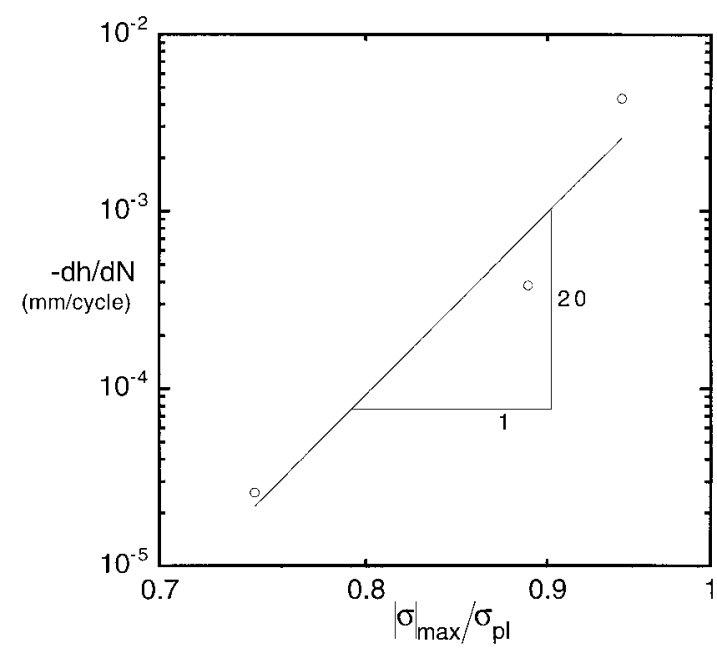

Fig. 13. The dependence of specimen shortening rate upon cyclic load level for compression-compression loading of Alporas. Relative density $=11 \%, R=0.1$.

for cyclic loading. For both monotonic and cyclic loading, crushing is by the plastic collapse of cell edges. The collapsed cells are associated with, and may be induced by tensile cracking of the cell faces.

The rate of shortening of the Alporas specimen in the band broadening stage is particularly sensitive to the applied load level. This is evident from a $\log -\log$ plot of the rate of specimen shortening $\mathrm{d} h / \mathrm{d} N$ vs stress level $|\sigma|_{\max } / \sigma_{\mathrm{pl}}$ in Fig. 13. The response is adequately described by a power law with a slope of 20. Compression-compression fatigue tests were also performed on Alporas at a load ratio $R=0.5$. In this case, the sequence of crushband formation resembled that observed in a monotonic test: multiple crush bands formed with increasing cycles. This behaviour appears to be identical to that observed by Sugimura et al. [7] in their fatigue tests on Alporas foam at $R=0.1$.

\section{CONCLUDING REMARKS}

We have measured $S-N$ fatigue curves for Duocel and Alporas foams by defining failure as (i) material separation in tension-tension fatigue, and (ii) an accumulated compressive strain of $2 \%$ in compression-compression fatigue. The fatigue limit is taken as the maximum value of stress in the fatigue cycle, $|\sigma|_{\max }$, corresponding to a fatigue life of $10^{7}$ cycles. The fatigue ratio $|\sigma|_{\max } / \sigma_{\mathrm{pl}}$ is plotted against relative density in Fig. 14 for the Duocel and Alporas foams, and is compared with existing data for other aluminium alloy foams-Alulight foam [16] and an Alcan foam [17]. We conclude that the magnitude of the fatigue ratio is almost independent of mean stress and is independent of the relative density of the foam. For comparison purposes, the endurance limit normalized by the yield strength of aluminium alloys has been added

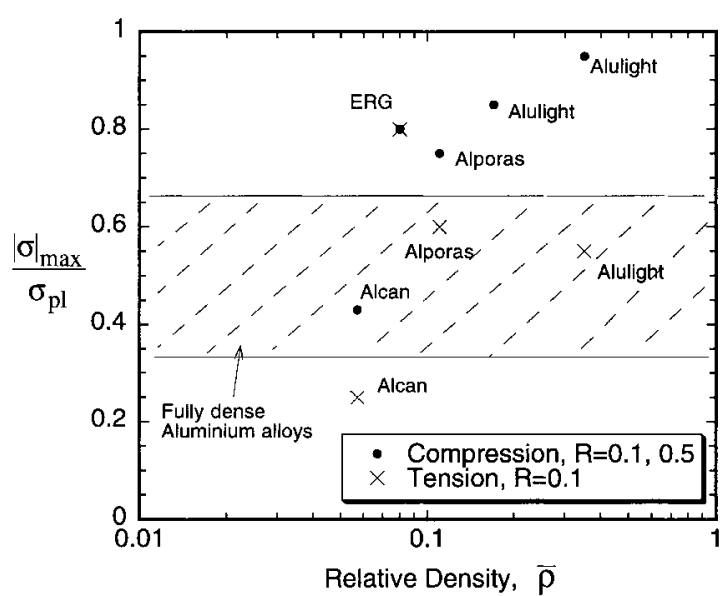

Fig. 14. The fatigue limit (the maximum value of stress $|\sigma|_{\text {max }_{7}}$ in the fatigue cycle, corresponding to a fatigue life of $10^{7}$ cycles) of Duocel and Alporas compared with that of two other aluminium foams, Alcan and Alulight. The scatter band of the fatigue limit of fully dense aluminium alloys has been added for $R=0.1$.

to the figure for tension-tension fatigue at $R=0.1$. With the exception of the highly heterogeneous Alcan foam, it is clear that the fatigue performance of the foams is comparable to that of fully dense aluminium alloys.

Acknowledgements - The authors are grateful to DARPA/ ONR for their financial support through MURI grant number N00014-1-96-1028 on the Ultralight Metal Structures project at Harvard University. A.-M. H. also wishes to thank the Newton Trust for financial support.

\section{REFERENCES}

1. Ashby, M. F., Evans, A. G., Hutchinson, J. W. and Fleck, N. A., Metal foams: a design guide. CUED/CMICROMECH/TR. 3, 1998.

2. Sugimura, Y., Meyer, J., He, M. Y., Bart-Smith, H., Grenestedt, J. and Evans, A. G., Acta mater., 1997, 45, 5245 .

3. Gioux, G., McCormack, T. M. and Gibson, L. J., Int. $J$. Mech. Sci., in press.

4. McCullough, K., Fleck, N. A. and Ashby, M. F., Acta mater., to be published.

5. Chen, C., Lu, T. J. and Fleck, N. A., J. Mech. Phys. Solids, submitted.

6. Grenestedt, J., J. Mech. Phys. Solids, 1998, 46(1), 29.

7. Sugimura, Y., Rabiei, A., He, M. Y., Evans, A. G., Harte, A.-M. and Fleck, N. A., J. Mat. Sci. Engng A, in press.

8. Banhart, J. and Brinkers, W., J. Mater. Sci., submitted.

9. Murphy, A. M., Ashby, M. F. and Fleck, N. A., Metallography and image analysis of metallic foams. CUED/C-MICROMECH/TR. 1, 1998.

10. Bart-Smith, H., Bastawros, A.-F., Mumm, D. R., Evans, A. G., Sypeck, D. J. and Wadley, H. N. G., Acta mater., 1998, 46, 3583.

11. Andrews, E. W., Gioux, G., Onck, P. and Gibson, L. J., Mater. Sci. Engng A, submitted.

12. Andrews, E. W., Sanders, W. and Gibson, L. J., Mater. Sci. Engng A, submitted. 
13. Gibson, L. J. and Ashby, M. F., Cellular Solids. Cambridge University Press, Cambridge, 1997.

14. Fleck, N. A., Kang, K. J. and Ashby, M. F., Acta metall. mater., 1994, 42(2), 365.
15. Boller, C. and Seeger, T., Materials Data for Cyclic Loading. Elsevier Science, Oxford, 1987.

16. McCullough, K., Unpublished research, 1998.

17. Olurin, O. B., Unpublished research, 1998. 